\title{
ELECTRONIC SOCIAL NETWORKING SITES AS A UNIVERSAL TOOL FOR DEVELOPING FUTURE TEACHERS' DIGITAL COMPETENCE
}

\author{
Viktoriia Hrynko \\ SHEI “Donbas State Pedagogical University”, Sloviansk, Ukraine \\ grinko2703@gmail.com
}

\begin{abstract}
The aim of the research is to study the opportunities of using the electronic social networks for developing future teachers' cognitive, creative, communicative and collaborative skills. The research was conducted at Donbas State Pedagogical University. 90 future primary school teachers and 40 university lecturers are involved in the research work that includes the use of social networks for developing cognitive, creative, communicative, and collaborative skills while studying the university courses. The research results are presented as the comparative analysis of the indicators of future teachers' cognitive, creative, communicative, and collaborative skills which were obtained at the initial (2014) and final (2018) stages of the experimental programme. The author analyses the research results according to five blocks: students' preference and motivation to use electronic social networking sites; the use of the electronic social networking sites for developing the cognitive skills; the use of the electronic social networking sites for developing creative skills; the use of the electronic social networking sites for developing collaborative skills; the use of the electronic social networking sites for developing communicative skills. The author claims that future teachers' digital competence improves while taking part in individual and group learning; in personal learning; while using social networks for the purpose of informing about the university events, for conducting extracurricular activities, non-formal and informal education, project activities etc. It was proved that the conditions, which contribute to the successful implementation of social networking sites in the educational process of higher educational institution, include an active, conscious and cultural use of electronic social networking sites by students, as well as university lecturers' understanding and concern about implementing these educational digital resources in their professional activities.
\end{abstract}

Keywords: digital humanistic pedagogy; digital competence; digital educational resources; electronic social networking sites; future teachers.

\section{Introduction}

Over the past few years, the rapid development of digital technologies causes an irreversible transition from traditional methods of personal growth to innovative ones, using modern digital tools, in particular electronic social networking sites that are characterised by the strong potential to bring people together. There is an urgent need to develop future teachers' professional skills to implement electronic social networking sites for their professional improvement.

The new branch of pedagogical science - digital humanistic pedagogy - has emerged. It is considered to be a study about regularities of building the positive integrated pedagogical reality provided that physical and virtual (created with digital technologies) learning environments are converged. Its emergence updates the opportunities to implement electronic social networking sites in the system of future teachers' professional training. Training analytics of implementing electronic social networking sites as tools for organising and realising educational activities in higher educational institutions enables monitoring the changes in motivation, preferences, and levels of development of future teachers' cognitive, creative, communicative and collaborative skills.

The founders of the digital humanistic pedagogy in Ukraine are outstanding scientists in the sphere of information technologies in education - Bykov, Leshchenko and Tymchuk (2017). Based on the analysis of the foreign and national experience of the convergence of information and communication technologies with humanistic and educational practices, they offered first to use the category "digital humanistic pedagogy" in 2006, emphasising the development of a personality by means of the digital technologies.

The issue of forming and developing educators' professional competence by the use of the digital educational technologies and resources is highlighted in the works by Ukrainian scientists Bykov, Leshchenko and Tymchuk (2017), Sokoliuk (2016), Yatsyshyn (2014) and others.

We analysed foreign scientific works in scientometric databases Web of Science, Scopus and Education Resources Information Centre regarding the clarification of the concepts "digital competence" and "digital literacy" which were made by a group of scientists from Sweden - Spante et al. (2018). The analysis of information literacy and digital competence of pedagogical university students was made by Spanish scientists - Rodríguez, Méndez, and Martí (2018). Australian scientists Ridout and Campbell (2018) made the research, aimed at implementing electronic social networking sites for supporting children and teenagers'

Hrynko, V. (2019). Electronic social networking sites as a universal tool for developing future teachers' digital competence. Advanced Education, 12, 64-73. DOI: 10.20535/2410-8286.168076 
mental health. The research of digital competence through using electronic social networking sites in educational process was made by Eyo (2016). The researches by Sadowski, Pediatis, and Townsend (2017) showed how the students used electronic social networking sites for the personal activities and the one connected with learning, as well as how students perceived their influence on the educational experience.

Issa (2016) turned to the problem of online learning in higher education, offering the possibilities to implement social networking sites and possible risks, which she associated with their use in the sphere of education in different regions of the world, such as Europe, America, Africa, Asia etc. American scientists Carpenter and Krutka (2015) described the role of social networking sites in teacher training, paying a special attention to the methods of increasing the potential of this technology. They considered the issue of accessibility of social networking sites. In their works, the social networking sites are presented as a means of the extended interaction of learning process participants, the discussion, the collaboration, the feedback, the consultation, and support.

Gillen and Merchant (2013) devoted their research to studying the issues of involving students in the groups in social networks. They considered the opportunities of using social networks, in particular, Twitter, for developing new forms of digital communication that contributed to developing the digital literacy. Hutchinston and Wang (2012) highlighted the issue of involving future teachers in the virtual communities, emphasising their role in reducing the teachers feeling of isolation at the initial stages of their career.

The researchers Kumar and Vigil (2011) claimed that although the vast majority of today's students are knowledgeable about the matters of using social networking sites, they use these sites not for studying, but for entertainment. So Foulger et al. (2016) tried to determine the ways of using social networking sites for achieving educational and professional goals. Allen, Caple, Coleman and Nguyen (2012) studied the issue of university students' professional development through involving them in the active discussion of learning content in networks, as well as in doing their own blogs.

Thus, the scientists explained that the use of electronic social networking sites in educational activities was regarded as a learning tool (creating web content, personal interaction, defining integrated individual trajectories), an effective environment for educational communication and collaboration. Despite the close attention of the scientists to solving the problem of developing key skills of XXI century, the issue of implementing electronic social networking sites for improving future primary school teachers' professional development is not highlighted properly.

The purpose of the paper is to study the opportunities to use electronic social networking sites for developing future teachers' cognitive, creative, communicative, and collaborative skills.

The importance of the future teachers' skills to navigate the information space, to search, to create, to analyse critically information messages and exchange them, reflecting personal activities, causes the formulation of the research hypothesis. The main research hypothesis lies in the fact that the use of electronic social networking sites in educational process contributes to students' professional development if they have the motivation to implement them and skills to use them as the tools for developing cognitive, creative, communicative, and collaborative skills.

Based on the foundations of digital humanistic pedagogy, we developed the principles of implementing electronic social networking sites in teacher training:

- using electronic social networking sites in various forms and types of learning activities should be led to adding cognitive and creative characteristics to the educational process, as well as it should provide openness, flexibility, democratisation, differentiation, individualisation, and comfort that make the educational development attractive for citizens in continuous training;

- developing future teachers' integrated thinking that is aimed at perception, projection, realisation and assessment of educational process that is carried out through connecting human resources and digital technologies and that is a necessary condition for ensuring the quality of education in the information society;

- comprehending by future educators the opportunities to implement digital technologies, skills to expand the channels of transferring, perceiving and reproducing the information for creating positive pedagogical reality that is an important motivation factor of the high-quality professional activities;

- the skilled use of electronic social networking sites increases the operation capabilities of pedagogical reality, deepens its virtual characteristics that create the conditions for spiritual and creative development of both teachers and learners.

Thus, implementing the electronic social networking sites in educational process can contribute to students' professional development as a result of the revitalisation of cognitive activities, and increase the motivation of educational process subjects to solve the educational problems. 


\section{Research Methods}

The research and experimental work was conducted at the Faculty of Primary, Technology and Vocational Education of SHEI "Donbas State Pedagogical University" (Sloviansk, Ukraine). Overall the research included 90 future primary school teachers and 40 lecturers (28 women and 12 men). The age of students, who studied to gain the first higher education, speciality "Primary Education", was between 18 and 23. The Ukrainian girls dominated in the experimental activities. The age of lecturers was between 30 and 60. The research was carried out during the period 2014-2018. At the beginning of the first academic year (2014-2015), we studied the current motivation to use electronic social networking sites and skills to implement them in the learning and professional activities of the first-year students in the day-time and parttime form of training.

Based on the research results and the author's concept of designing digital educational technologies in future primary school teachers' training, the experimental programme was designed which included teaching students to use electronic social networking sites for developing cognitive, creative, communicative, and collaborative skills while studying the courses "Information Technologies in Teachers' Professional Activities", "Modern Information technologies", "Basis of Scientific Researches", "Educational Informatics", while implementing international projects, teaching practice, and informal educational activities at out-of-class time during four years of study.

The accomplishment of the set goal was performed by doing such tasks:

- to develop students' understanding of the concept of electronic social networking service and its importance in the information society;

- to show students the educational opportunities and the possible factors of the risks on electronic social networking sites;

- to teach students to regulate their behaviour on electronic social networking sites while communicating in the virtual reality;

- to teach to use electronic social networking sites as a tool for researching, learning, exchanging the informative messages, creative self-realisation, communication, collaboration, entertainment and rest.

We give examples of activities that were held. In training classes "Internet Safety Rules", "The Behaviour Culture on the Internet", "Cyberbullying - How to Confront", "I'm on the Internet", "Death Games" (1-4 years of study), future teachers analysed cases, acted out scenes, took part in debates and discussions, gave examples from their life, and tried to figure out how to behave in different situations that could appear in the virtual environment.

While conducting the project "Learning Scientific Conference", which was realised in the course "Basis of Scientific Research" (the second year of study), the students held the conference "Information Society: Realias and Problems". They prepared interesting and informative reports and scientific papers on clip thinking, prevention of computer addiction, digital dementia and cyberbullying. All the reports had unconventional examples, which reflected the young generation's thoughts about advantages and disadvantages of information society. Also, the reports were accompanied by the presentations.

While studying the course "Modern Information Technologies" (the third year of study) the special attention was paid to the issue of using social networking sites in the professional activities. Students analysed the content of professional communities, learned the opportunities for professional selfdevelopment and self-education, learned to create and moderate the virtual communities, using various networking educational digital resources, and designed didactic materials and web quests. On Safer Internet Day the flash mob was held. The participants had to formulate the promises about communication in electronic social networks that were disseminated with hashtag \#SAFERINTERNETDAY on their personal pages. At the end of the experimental programme (2017-2018), the final research was conducted to study the level of skills to use electronic social networking sites in training activities for the professional development of students and faculty lecturers.

In the study we used such methods as questionnaire, survey, observation, netnography, as well as the methods of analysis, comparison, and synthesis of obtained results for determining the present motivation of using electronic social networking sites and skills to use them in training and teaching activities of both students and faculty lecturers in educational process. The experimental programme took place from 2014 to 2018.

The questionnaire of the students and lecturers was held on the basis of modern service GoogleForms. This service gives an opportunity to make a questionnaire of any type and any theme. The author can choose the number of answers in accordance with the theme chosen.

The advantage of GoogleForms in comparison with other services for making questionnaire is that all the answers in GoogleForms are automatically streamlined and systemised in the WordExcel table, graphic system, diagram (according to the variants of answers) or in a separate web-page. The number of questions 
can be unlimited. One more positive point concerns the design of the questionnaire page, as the certain page design helps to reflect the theme of the questionnaire better.

During 2014-2015 and 2017-2018 academic years we conducted the questionnaire by means of distributing the forms through mail services, all the answers were anonymous. In the questionnaire during 2014-2015 academic year, 90 persons were involved. During 2017-2018 academic year, 72 persons, all the respondents, admitted that they used electronic social networks. Apart from deciding on preference and motivation of using the social networking sites, the questions were aimed at diagnosing the ability to use social networks for developing cognitive, communicative, and collaborative skills.

\section{Research Results}

The study results, focused on learning to use electronic social networks for developing future primary school teachers' cognitive, creative, communicative and collaborative skills on the condition of existing motivation to use them, are presented in comparative analysis of indicators, obtained at the initial (2014) and final (2018) stage of research.

The analysis of the survey includes five blocks.

Block I. Students' preference and motivation to use electronic social networking sites.

In 2014-2015 academic year, 100\% of respondents preferred the social network "VKontakte". The second most popular one was "Odnoklassniki" $(15,6 \%)$, the third most popular was "Facebook" $(7,8 \%)$. The social networking site "Twitter" had $1.1 \%$.

May 16, 2017 the president of Ukraine P. Poroshenko introduced the decision of The National Security and Defense Council of Ukraine on Impositions of Sanctions on the number of Russian social networks, Internet companies and TVdiagnosing. So the list of electronic social networking sites in the questionnaire was changed - "VKontakte" and "Odnoklassniki" were excluded.

In the 2017-2018 academic year, 97,2\% of respondents voted for the network "Instagram", $88,9 \%$ of respondents claimed that they used the network "Facebook", 8,3\% - "Twitter", 2,7\% - "Google+", 20,8 \% other networking sites. According to the recorded changes of the preferences of choosing electronic social networking sites among young people, such changes had the reasons of the political nature. The research, conducted in 2014-2015 academic year, proved that 39,3\% of the students surveyed were present at the social networks for 2 or 3 hours. 24,7\% of the students surveyed answered that they spent only 1 or 2 hours on the social networking sites. $27 \%$ of respondent answered that they spent the whole day on the social networking site, whereas $27 \%$ of students responded that they spent only 10-30 minutes on the social networks. The research, conducted in the 2017-2018 academic year, showed that the students spent more time on the social networking sites: $95,8 \%$ of students spent the whole day, $2,7 \%-1$ or 2 hours, $1,5 \%-10-30$ minutes.

Answering a question about the registration period, in 2014-2015 58,9\% of respondents said that they had been using the social networking site for more than 4 years, 25,6\% informed that they signed in 3 or 4 years ago, 14,4\% - 2 or 3 years ago. In 2017-2018, the respondents answered that $47,2 \%$ signed in 3 or 4 years ago, $52,8 \%$ signed in more than 4 years ago.

Responding to the question "Will you feel sorry if you learn that your favourite social networking site is closed?", in 2014-2015 44,9\% of the students surveyed agreed, 37,1\% were neutral, 6,7\% said no. In $2017-$ 2018 , only $2,7 \%$ of respondents were neutral, the rest of the students accepted that they would feel sorry.

Answering the question about the initial goal of the registration, $68,5 \%$ of the students surveyed answered that they needed communication. Meanwhile, 49,4\% of students responded that the social networking sites helped them study, $14,6 \%$ said that they used the certain networking site as it gave them an easy access to media files. In 2017-2018, 90,3\% of respondents signed in for communicating and 58,3\% used it for the study (work).

"How often do you feel annoyed or anxious when you can't access your account on the social networking site?" - in 2014-2015 only one student answered this question "often", 53,9\% answered "sometimes", and 44,9\% answered "never". In 2017-2018, 8,3\% of the students surveyed answered "often", $61,1 \%$ - "sometimes", 30,6\% - "rarely".

In 2014-2015, 48,3\% of students didn't think that their life without the social media was boring, empty and joyless, 46,1\% "rarely" had this feeling, 5,6\% - "often". In 2017-2018, 80,5\% of the respondents felt this emptiness, $1,4 \%$ "never" felt it, $7 \%$ - "often".

Block II. Diagnostics of using the electronic social networking sites for developing the cognitive skills.

Diagnostics of the level of developing the skills was realised on the basis of the analysis of responses to the questions. In 2014-2015, 79\% of respondents gave a negative answer, being asked if they used electronic social networking sites for searching the information for the study, $21 \%$ gave a positive answer. In $2017-$ 2018, the indicators changed greatly, 90,3\% gave a positive answer. In 2014-2015, 25,6\% of respondents 
agreed, answering the question "Do you check the information that you have read in the social networking sites?", 37,7\% answered "sometimes", 36,7\% said "never". In 2017-2018, the results were the following: $57 \%$ answered "yes, always", $25 \%$ - "sometimes", $18 \%$ - "no".

"Do you use the electronic social networking sites for self-education? How? (an open question)". In 2014-2015, we got $85,6 \%$ of positive answers concerning the knowledge which were connected to students' favourite activity types (recipes, improving their body, sport activities, handmade, travelling), 14,4\% of answers were negative. In 2017-2018, 94,4\% of respondents claimed that they used the electronic social networking sites for their professional self-education, they joined professional groups, subscribed to the useful pages for following the events (competitions, grants, workshops, webinars, conferences).

The next was the question that required the answer, reasoning the thoughts: "Do you feel the need to improve your knowledge about the opportunities of using the electronic social networking sites in the professional activities of a teacher?". In 2014-2015, 44,4\% of respondents said that they didn't feel such a need as the network site was not a working place for a teacher, 66,6\% said it was interesting. In 2017-2018, $100 \%$ of respondents answered positively about the possibilities of using the electronic social networking sites in their professional activities.

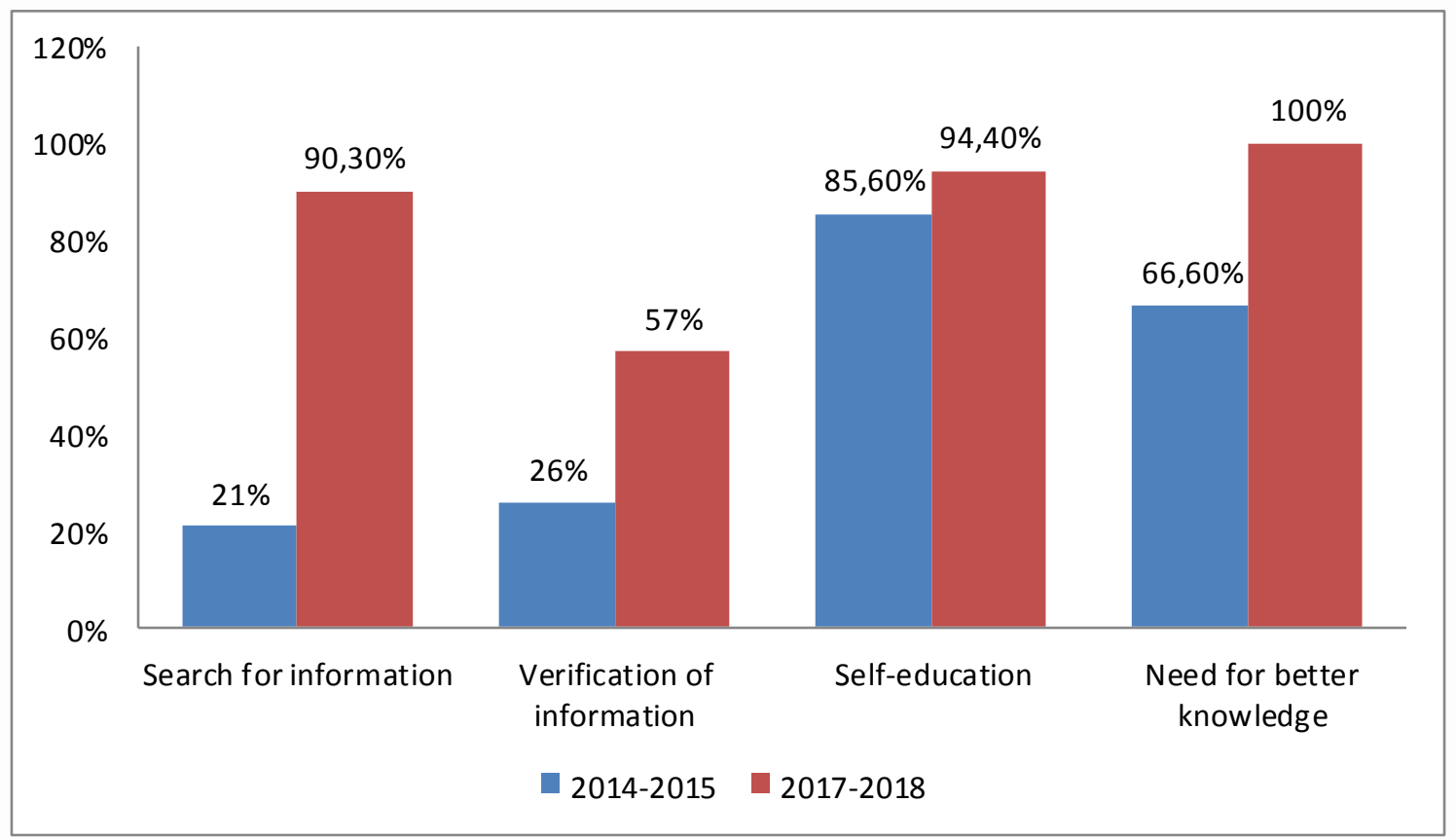

Figure 1. The comparison of using the electronic social networking sites for developing cognitive skills in the academic years 2014-2015 and 2017-2018

Block III. Diagnostics of using the electronic social networking sites for developing creative skills.

Answering the question "How often do you change the way your page looks?", in 2014-2015 40\% of respondents said that they did it almost "never", in 2017-2018 the number of indifferent persons decreased to $29,1 \%$. In $2014-2015,35,5 \%$ of persons surveyed answered "sometimes", whereas $24,5 \%$ claimed that they updated the information and photos regularly. In 2017-2018, 30,5\% said they sometimes updated the information, 40,4\% - regularly. Answering the question "Do you use the editor before publishing the photo/video?", in 2014-2015, only 20\% said "yes, always", in 2017-2018, 59,7\% of respondents claimed they always edited photo/video.

Answering the question "Do you express your own thoughts/ observations/ impressions or copy others' sayings when you publish posts?", in 2014-2015 58,8\% answered they copied the others' sayings, 12,2\% sometimes theirs, sometimes others', $12,5 \%$ - only their own thoughts, $16,5 \%$ claimed that they hardly ever published posts. In 2017-2018, only 8,3\% respondents said that they copied other people's sayings, 34,7\% sometimes theirs, sometimes others', $45,9 \%$ - only their own thoughts, $11,1 \%$ claimed that they almost never published posts. In 2014-2015, answering the question "Do you try to make your page/account unique and interesting?", $28,8 \%$ of future teachers surveyed gave a positive answer, $71,2 \%$ claimed that they didn't see the point. In 2017-2018, the indicators changed: $45,8 \%$ of respondents answered positively, 54,2\% said they didn't see the point. 


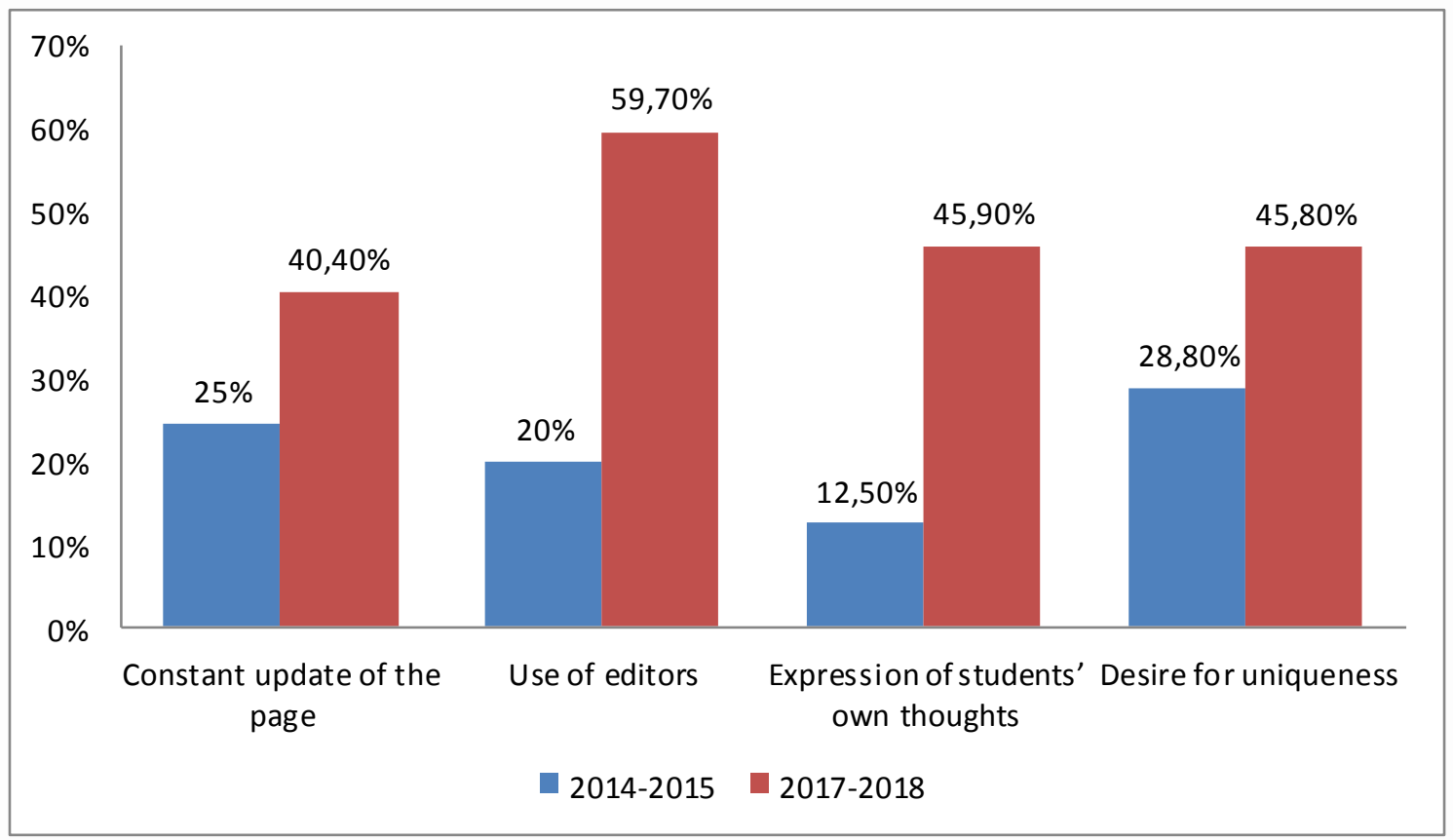

Figure 2. The comparison of using the electric social networking sites for developing creative skills in 2014-20015 and 2017-2018

Block IV. Diagnostics of using the electronic social networking sites for developing collaborative skills.

Answering the question "How many groups have you joined?", in 2014-2015 the following responses were given: $27,7 \%$ joined 1-10 groups, $60 \%$ - 11-19 groups, 12,3\% - more than 20. In 2017-2018, 20,8\% of respondents joined 1-10 groups, 38,8\% - 11-19 groups, 40,4\% - more than 20. Answering the question "Do you have the same groups with your groupmates for discussing the learning questions?", $100 \%$ of respondents gave positive answers both in 2014-2015 and 2017-2018, it's necessary to emphasise that all the groups were closed. Answering the question "Do you use social networking sites for working together while learning?", in 2014-2015 10\% of respondents agreed that they studied together and discussed the learning material, $78,8 \%$ of respondents claimed that they exchanged the materials and shared their notes, $11,2 \%$ said that they discussed only organisational issues. In 2017-2018, 94,4\% of respondents answered that they exchanged the materials and shared their notes and, furthermore, 44,4\% accepted that they studied together and discussed learning materials.

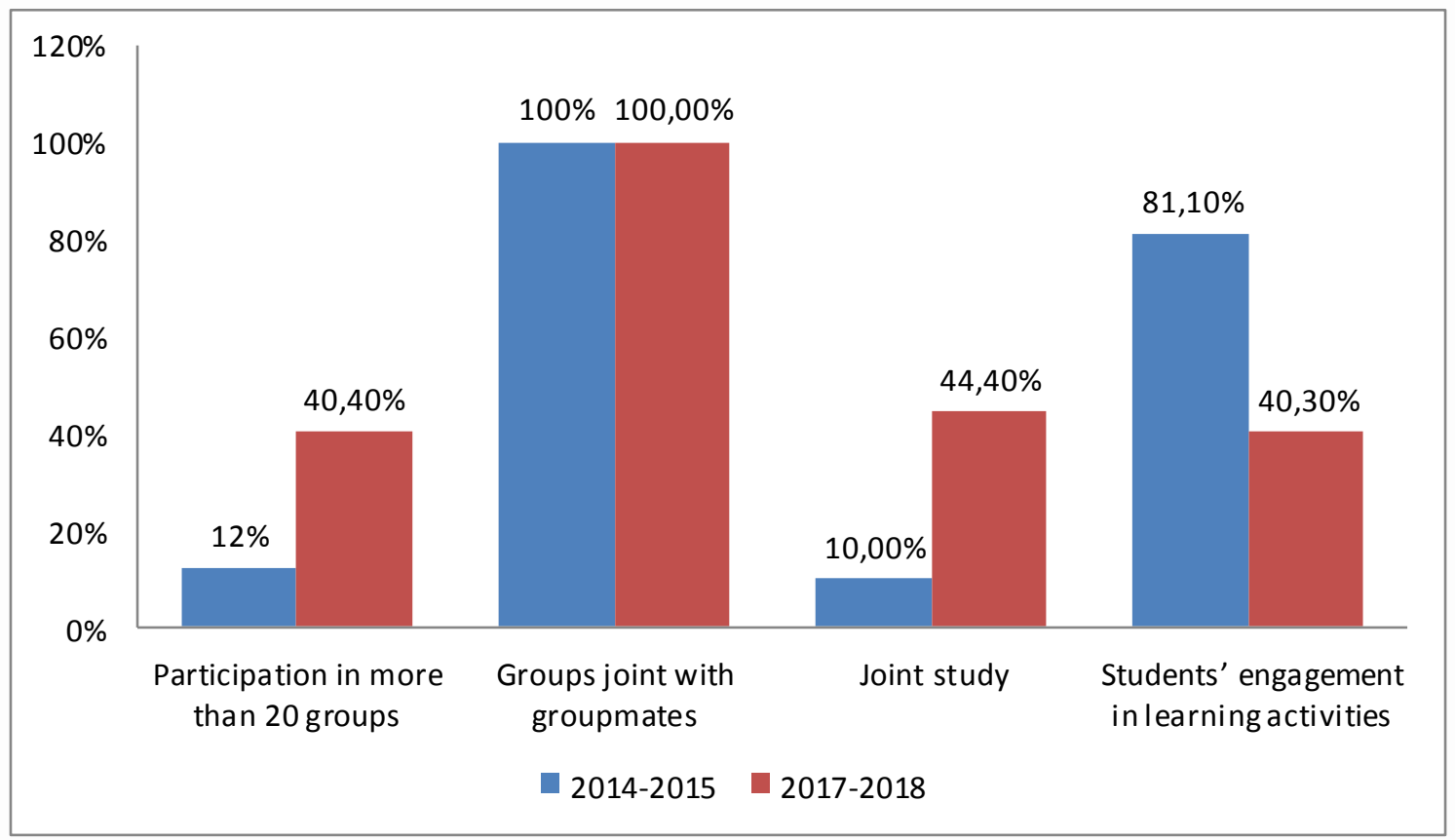

Figure 3. The comparison of the development of collaborative skills based on the electronic social networking sites in 2014-2015 and 2017-2018 
Being asked if they got the tasks of carrying out the projects that involved the activities in social networking sites, in 2014-2015 81,1\% answered that they didn't do such tasks, in 2017-2018 40,3\% of respondents denied doing such tasks, $59,7 \%$ took part in carrying out project activities.

\section{Block V. Diagnostics of using the electronic social networking sites for developing communicative skills.}

In 2014-2015, having friends on the electronic social networking sites was important for $12,4 \%$ of recipients, but in 2017-2018 the number of students, who appreciated a large number of friends, rose to $98,8 \%$. In 2014-2015, 24,7\% of respondents felt "out of the loop" if they didn't get onto the electronic social network, 13,5\% said "absolutely no", but more than 55,1\% had a neutral attitude to this. In 2017-2018 academic year, the indicators changed: $83,3 \%$ felt "out of the loop", $7 \%$ - "absolutely, no", 9,7\% had a neutral attitude to this. 69,7\% of respondents in 2014-2015 and 56,9\% in 2017-2018 used the electronic social networking sites to communicate with their old friends; $24,7 \%$ and $6,9 \%$ couldn't say for sure, $5,6 \%$ in 2014-2015 and 36,2\% in 2017-2018 - to establish new contacts. In 2014-2015, 55,6\% of people surveyed believed that they used the electronic social networking sites to get information about their friends, colleagues, and classmates; $32,2 \%$ of respondents couldn't say for sure, $12,2 \%$ gave a negative answer. The results of the survey in 2017-2018 changed slightly.

The communication has been a priority basis of the electronic social networking sites, however, modern youth is so used to this services that the founders have to add something new to attract the audience. Nowadays apart from the opportunity to communicate, every social networking site gives the users a large number of other services (listening to audio recordings; watching videos; participating in games, competitions, marathons, and charitable events; providing marketed services).

Answering the questions about the additional opportunities of the electronic social networking sites, the respondents can give some answers simultaneously as everybody uses various additional options to certain degrees. Communication is the main thing, 69,7\% of respondents accepted this in 2014-2015 and 90,3\% - in 2017-2018. In 2014-2015, 38,2\% of respondents preferred listening to music along with communication, $31,5 \%$ (2014-2015) attended the social networking site to follow the news, in $2017-2018-80,5 \%, 12,4 \%$ and $11,1 \%$ simply watched the certain videos, $5 \%$ of people surveyed used the social network to play different entertaining games. As we can see, young people are interested in additional services, but the communication is the most essential.

With the emergence of additional opportunities, the communication has become diverse. Dialogues, discussions, comments and other expressions of the interest in the conversation appeal new audience. Most students at the faculty $(72,4 \%)$ chose communication through the private messages, $21,8 \%$ of respondents communicated actively with everyone. $5,7 \%$ of interviewees on the social media were interested only in certain issues. The indicators in 2017-2018 changed slightly.

Answering the question that concerned the upgrade of the posts on the social networks, in 2014-2015, $46,1 \%$ of respondents said that they never felt such a need, $42,7 \%$ claimed that they had such a feeling, but very seldom. $6,7 \%$ of respondents admitted that they felt such a need regularly, 2,2\% answered that they often felt like they needed to upgrade the posts. In 2017-2018, the situation changed, 34,7\% answered they never had such a need. 20,3\% had such a need very rarely, 33,3\% felt such a need regularly, 11,7\% had such a feeling frequently and regularly. Answering the question about the way to get more likes for a certain photo or a post, in 2014-2015 we found out that $10,1 \%$ posted the content for this purpose, $64,1 \%$ of respondents answered that it didn't matter for them, $20,2 \%$ of students said that it was important, but they didn't follow that; $12,5 \%$ posted nothing at all.

To analyse comparatively, we take only the indicators that have changed significantly (Figure 4).

It's impossible to implement the electronic social networking sites in the educational process without having the positive attitude to this phenomenon, so the questionnaire of the faculty lecturers was aimed at determining both their attitude and readiness to implement the electronic social networking sites in their professional activities. In 2014-2015, only 16 lecturers agreed to fill in the questionnaire, the rest refused to answer the questions, explaining that they weren't interested in that. In 2017-2018, 24 of 36 lecturers filled in the form. Comparing the number of the persons surveyed, we can conclude that the number of lecturers, who accept the use of electronic social networking sites in their professional activities, has increased. In 2014-2015, only $25 \%$ of lecturers said that they used the networks in their professional activities, whereas in 2017-2018 75\% of lecturers surveyed claimed that they used the electronic social networking sites actively for communicating with students, advised their students' educational communities and participated in discussing the professional issues. The group for faculty lecturers and students has been working actively 
since 2016 due to which the useful and interesting information is spread, they exchange photos and videos of events, everyone has an opportunity to feel like a part of the faculty community.

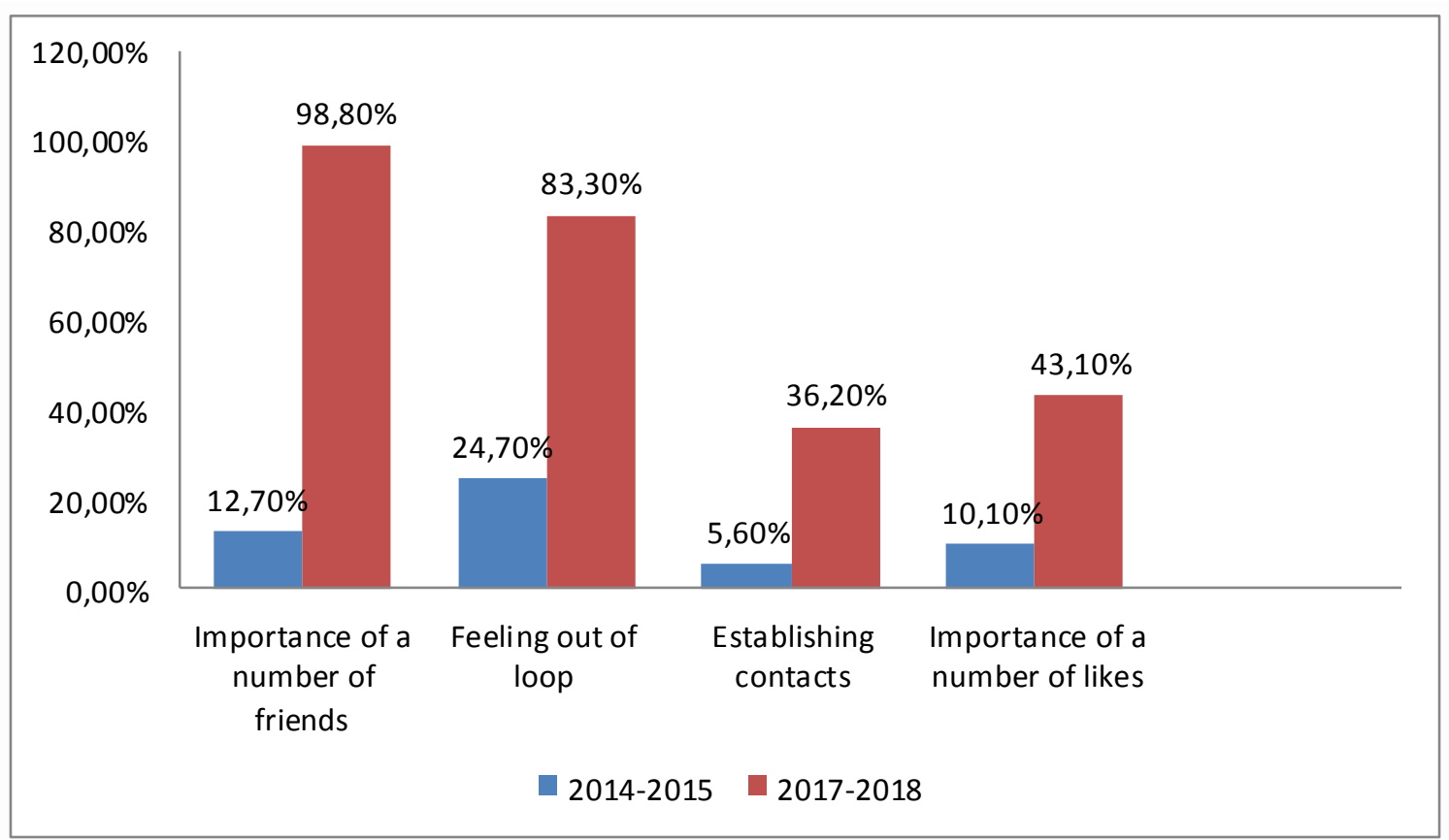

Figure 4. The comparison of the development of communicative skills based on the use of electronic social networking sites by students in 2014-2015

\section{Discussion}

The analysis of the obtained data of studying the students' preference and motivation to use electronic social networking sites prove that accessibility and high quality of the Internet, as well as the low price of smartphones, contribute to turning the electronic social networking sites into a part of everyday life of today's youth. The students' motivation to use electronic social networking sites is at the sufficient level, however, it has grown sufficiently at the end of the experiment. In our opinion, an announcement about the permanent presence at the network by $95,8 \%$ of students shows that digital technologies accompany the students in curricular and extra-curricular activities. The strong positive sensitive and emotional attitude of students to the present access to the electronic social networking sites proves their ability to integrate the informative data that are found in the physical and virtual reality simultaneously. The research by Abdelraheem and Ahmed (2018) on the influence of using social network mobile applications on the students' public life proves that the active use of social networks doesn't have a negative impact on the educational process.

Diagnostics of using the electronic social networking sites for developing the cognitive skills proves that during four years of the experimental programme, which is described above, the use of electronic social networking sites has become more conscious and critical. The students have an opportunity to evaluate the educational potential of social networking sites. The scientist Akçayır (2017) claims that students use the electronic social networking sites for getting information more that for spreading it.

The analysis of obtained results of diagnostics of using the electronic social networking sites for developing the creative skills shows that students proceed gradually from the position "I watch, I read" to the role of active users, upgrading their pages continuously, establishing the informative messages, posting their own publications, trying to create the unique content of their profile. This confirms the students' attempts to identify themselves in the virtual environment as creative personalities. The research by Allen, Caple, Coleman and Nguyen (2012) also proves that social networking sites, in particular, Facebook, contribute to developing students' creative skills. They see the goal of their study in involving the students to the distribution of learning content through social networks. They also say that the maintenance of students' pages gives them the freedom to create and publish materials and, as a result, contributes to the development of students' creative skills.

As the research shows, the training of how to use electronic social networking sites contributes to the development of students' creative skills, that the majority of students confirm. These students prefer writing their posts in a creative way, using actively the author's photo and video, decorating their pages. The 
realisation of the creative expression is based on the improvement of skills to use the photo, video, graphic and text editors.

The results of studying the use of electronic social networking sites for developing the collaborative skills demonstrate that the students use the electronic social networking sites actively for establishing their joint learning activities, so they join a large number of virtual groups. The increase of the number of students, who take part in fulfilling the project tasks through the electronic social networking sites, confirms that the university lecturers turn the students to the active use of electronic social networking sites in their educational activities. Since 2016 in Facebook the group of the faculty has worked successfully. Both students and lecturers distribute useful and interesting information, share photos and videos of different events. This group helps everybody feel like a part of the faculty community. The received results are consonant with the research by Schindler (2017) who claims that engagement of the students to the joint learning activities increases due to the use of electronic social networking sites (Twitter, Facebook). The received results are aligned with the research results by the Spanish scientists Fraile, Peñalva-Vélez, and Mendióroz Lacambra (2018). They say, as a result of self-assessment of the development of digital competence, that students claim they are ready for interaction and joint use of information.

According to the data of the survey, aimed at diagnostics of using the electronic social networking sites for developing the communicative skills, we can claim that for four years the electronic social networking sites have started to play an important part in the life of future teachers as an effective tool for the communication and the acting environment of virtual communication. The results of the research by Sadowski, Pediaditis and Townsend (2017) prove that the main purpose of using the electronic social networking sites in the private life is to communicate with friends and to use them as a positive tool for making the interaction between both students and students, who study online, easier. The results received in 2018 about the use of electronic social networking sites for exchanging their notes differ in comparison with Guraya et al. (2018). In Ukraine, the future teachers use the social networking sites for this purpose more often than future doctors in Kuwait and Saudi Arabia - 94,4\% and 38\% respectively.

Thus, we think that the implementation of the electronic social networking sites contributes to developing democratic open cooperative relationships between lecturers and students, as well as it influences positively the sensitive and emotional characteristics of the learning environment. We agree with the conclusions made by Dumpit and Fernandez (2017) if the lecturers integrate social networks into their courses, students perceive positively this form of learning. The university students' expectations about the use of electronic social networking sites for educational purposes are determined in the research made by Akçayır (2017): as the survey shows, students expect that the lecturers disseminate learning and supplementary materials for the course and video recordings of the lessons in the network. More than half of the students surveyed (53\%) try to communicate with lecturers in the social networks. These results correlate directly with the data of our research where we have found out that $75 \%$ of university lecturers communicate actively in the social networks for educational purposes, spread the learning materials for the students, and give methodological tips.

\section{Conclusions}

The active use of the electronic social networking sites in the process of future teachers' training is both the response to the challenges of the time and the educational need of all the participants of educational process. While doing the research, the opportunities of using the electronic social networking sites are revealed for establishing different forms of educational process: individual, group, personal, project, blended and distance learning; for establishing curricular and extra-curricular activities, formal, non-formal and informal education.

While conducting the experimental programme, we confirm the hypothesis formulated at the beginning of the experimental programme. The analysis of the research results proves that the use of electronic social networking sites in the educational process contributes to the development of students' cognitive, creative, communicative, and collaborative skills. We have found out that the conditions, which ensure the effective implementation of digital technologies in the educational process at tertiary educational institutions, include active, conscious and cultural use of electronic social networking sites by lecturers and students.

The important result of the empirical research is the improvement of students' skills to use the electronic social networking sites as a means of increasing the motivation, developing cognitive, creative communicative, and collaborative skills. So, the positive results of personal and professional development are achieved through the increase of the level of digital competence development.

The research doesn't cover all the aspects of formation and development of future primary school teachers' digital competence by the use of electronic social networking sites. The further study of the issue 
can be carried out in the direction of researching the opportunities of using digital technologies for developing safe behaviour on electronic social networking sites.

\section{References:}

Abdelraheem, A. Y. \& Ahmed, A. M. (2018). The impact of using Mobile Social Network Applications on Students' Social-Life. International Journal of Instruction, 11(2), 1-14. https://doi.org/10.12973/iji.2018.1121a

Akçayır, M. (2017). What do students think about SNSs in education? University students' perceptions, expectations, and concerns regarding educational uses of SNSs. Australasian Journal of Educational Technology, 33(5), 91-106. https://doi.org/10.14742/ajet.3097

Bykov, V., Leshchenko, M., \& Tymchuk, L. (2017). Tsyfrova humanistychna pedahohika [Digital humanistic pedagogy]. Kyiv, Ukraine: SAMMIT-KNYHA.

Dolores, M., Rodríguez, M., Méndez, V. G., Rodríguez, A. M., \& Rodríguez, M. (2018). Alfabetización informacional y competencia digital en estudiantes de magisterio. Profesorado, Revista de curriculum y formation del profesorado, 22(3), 253-270. https://doi.org/10.30827/profesorado.v22i3.8001

Dumpit, D. Z., \& Fernandez, Ch. J. (2017). Analysis of the use of social media in Higher Education Institutions (HEIs) using the Technology Acceptance Model. International Journal of Educational Technology in Higher Education, 14. https://doi.org/10.1186/s41239-017-0045-2

Eyo, M. (2016). Counselling implications of teachers' digital competencies in the use of Social Networking Sites (SNSs) in the teaching-learning process in Calabar, Nigeria. Cogent Education, 3. https://doi.org/10.1080/2331186X.2015.1128134

Fraile, M. N., Peñalva-Vélez, A., \& Mendióroz Lacambra, A. M. (2018). Development of Digital Competence in Secondary Education. Teachers' Training Educ. Sci., 8, 104. https://doi.org/10.3390/educsci8030104

Guraya, S. Y., Almaramhy, H., Al-Qahtani, M. F., Guraya, Sh. S., Bouhaimed, M., \& Bilal, B. (2018). Measuring the extent and nature of use of Social Networking Sites in Medical Education (SNSME) by university students: Results of a multicenter study. Medical Education Online, 23. https://doi.org/10.1080/10872981.2018.1505400

Merchant, G., Gillen, J., Marsh, J., \& Davies, J. (Eds). (2013). Virtual literacies: interactive spaces for children and young people. London: Routledge.

Ridout, B., \& Campbell, A. (2018). The Use of Social Networking Sites in Mental Health Interventions for Young People: Systematic Review. Journal of Medical Internet Research, 20(12). https://doi.org/10.2196/12244

Sadowski, C., Pediatis, M., \& Townsend, R. (2017). University students' perceptions of social networking sites (SNSs) in their educational experiences at a regional Australian university. Australasian Journal of Educational Technology, 33(5), 77-90. https://doi.org/10.14742/ajet.2927

Schindler, L. A., Burkholder, G. J., Morad, O. A., \& Marsh, C. (2017). Computer-based technology and student engagement: a critical review of the literature. International Journal of Educational Technology in Higher Education, 14. https://doi.org/10.1186/s41239-017-0063-0

Sokoliuk, O. (2016) Vkliuchennia merezhnikh sotsialnykh servisiv u diiuchi modeli organizatsii navchannia uchniv [Inclusion of social networking services in the existing model of organisation of students' learning]. Information Technologies and Learning Tools, 5(55), 55-66. Retrieved 15 April, 2019 from http://journal.iitta.gov.ua/index.php/itlt/article/view/1494/1088

Spante, M., Sofkova, S., Hashemi, M. L., Lundin, M. \& Algers, A. (2018). Digital competence and digital literacy in higher education research: Systematic review of concept use. Cogent Education, 5. https://doi.org/10.1080/2331186X.2018.1519143

Yatsyshyn, A. V. (2014) Zastosuvannia virtualnykh socialnih merezh dlia potreb zahalnoi serednoi osvity [The use of virtual social networks for the purpose of secondary education]. Information Technologies and Learning Tools, 19, 119-126. Retrieved 15 April, 2019 from http://nbuv.gov.ua/UJRN/itvo_2014_19_14.

Received: February 23, 2019

Accepted: May 23, 2019 